\title{
A Data-Driven Optimization Model of Important Multidimensional Factors Affecting College Students' Cognitive Engagement in Ideological and Political Theory Course
}

\author{
Liangliang Wang $\mathbb{B D}^{1,2}$ \\ ${ }^{1}$ School of Marxism, Northwestern Polytechnical University, Xi'an 710072, Shaanxi, China \\ ${ }^{2}$ School of Marxism, Xi'an Shiyou University, Xi'an 710065, Shaanxi, China \\ Correspondence should be addressed to Liangliang Wang; celiawong@mail.nwpu.edu.cn
}

Received 11 August 2021; Accepted 5 November 2021; Published 26 November 2021

Academic Editor: Punit Gupta

Copyright (c) 2021 Liangliang Wang. This is an open access article distributed under the Creative Commons Attribution License, which permits unrestricted use, distribution, and reproduction in any medium, provided the original work is properly cited.

\begin{abstract}
The optimization of important multidimensional factors is conducive to cognitive engagement, which is a crucial dimension of student engagement and plays a significant role in college students' learning of the Ideological and Political Theory Course. However, because there are many influencing factors associated with cognitive engagement, the influence mechanism and analysis strategy of this kind of model are relatively complex. In order to solve this research gap, this paper establishes an optimization model affecting Chinese college students' cognitive engagement in IPTC on the basis of sample collection and investigation. In this process, 4,700 questionnaires were distributed to 47 colleges and universities across the country, and copies were effectively recovered $(N=3992)$; the effective recovery rate was $84.94 \%$. Cronbach's alpha of 0.759 indicates that the scale has high reliability and Pearson's correlation coefficient $P \leq 0.001$ shows that the scale has good validity. The KMO value of 0.703 in the Bartlett sphere test also shows that the scale is suitable for factor analysis. Firstly, according to the method of factor analysis, there are six important factor dimensions affecting college students' cognitive engagement in the IPTC, namely, attention and motivation factor dimension, behavior and value attainment factor dimension, interest and practicality factor dimension, personality and will factor dimension, evaluation and time factor dimension, and knowledge and strategy factor dimension. Then, through descriptive analysis, it is found that personality and will factor dimension $(M=6.5837)$ plays a relatively major role while knowledge motivation dimension $(M=6.3505)$ has a weak impact on cognitive engagement. Finally, from linear regression analysis, there is a significant positive correlation between cognitive engagement and other variables. In addition, undergraduates are slightly lacking motivation in the learning of the course, and vigorously strengthening college students' cognitive engagement is still necessary, so as to effectively enhance the effectiveness of the IPTC in the future.
\end{abstract}

\section{Introduction}

Students' degree of cognition toward things determines their choice of direction when encountering difficulties, which further affects the individual's learning efficiency and development. In China, the Ideological and Political Theory Course (IPTC) is considered to be a course that is a key to implementing the fundamental task of moral education [1]. Only by fully understanding the content of the Ideological and Political Course and its significance can we better solve the fundamental problem of whom to train and how to train [2]. Only with full cognition of these things can college students understand the relationship between subject and object, develop good learning emotions, invest in mental endeavors, and transform all of those merits into positive actions.

1.1. Cognitive Engagement as a Part of Student Engagement. Tyler, an American educator, first used the concept of "student engagement" in the 1930s and 1940s [3] and it consists of two parts, namely, engagement in learning and learning time. Tinto argued that student engagement is the integration of society and study [4]. Astin put forward the student engagement theory, revealing the main content of student engagement from five aspects. The main content 
mainly includes the relationship between the time and quality of a student's investment in school life, as well as learning outcomes [5]. Scholars, such as Christenson et al., gain an understanding of student engagement through conceptual decomposition. According to the classification method, student's engagement can be divided into four aspects: academic engagement (refers to a student's involvement in learning tasks, credit growth, and time spent completing assignments), behavioral engagement (refers to a student's attendance, participation, and preparation for the course), cognitive engagement (refers to value relationships, etc.), and emotional engagement (refers to a student's understanding and sense of belonging to the school) [6]. Recently, student engagement has been measured by participation in online courses [7].

Cognitive engagement can affect the degree and quality of a student's efforts in classroom activities. Although researchers have emphasized psychological engagement in learning, the focus of each researcher has also been different. Corno and Mandinach formerly proposed that cognitive engagement was a dimension of student engagement and believed that self-regulated learning was a representative form of cognitive engagement, which can guide students to a higher level of reflection [8]. Connell and Wellborn concluded that the concept of cognitive engagement included problem-solving flexibility, hard work, and active response in the face of failure [9]. Newmann et al.[10] and Wehlage et al. [11] have emphasized the engagement of internal psychological quality in the learning process. As can be clearly seen, the study of cognitive engagement is typically accompanied by the study of learning strategies and selfregulation. Regardless of which aspect they focus upon, students will use metacognitive strategies to plan, monitor, and evaluate their cognition when completing a learning task [12]. Students will consciously use certain learning strategies to help themselves, and they will also use persistence or suppress interference to maintain their cognitive participation [13]. In short, students definitely use a variety of cognitive strategies in their learning, thereby reflecting a high degree of integration of various psychological connections. The essence of cognitive engagement lies in students' level of self-regulation level in learning [14]. Generally, with a higher level of cognitive engagement, students can use deeper cognitive strategies, develop a stronger thirst for knowledge, and engage in more active and in-depth thinking. On the contrary, students with relatively low levels of cognitive engagement typically mechanically memorize information in the form of superficial engagement. Cognitive engagement, therefore, refers to a student's degree of engagement in learning and the use of strategies $[15,16]$.

1.2. The Meaning of Cognitive Engagement in IPTC. Cognitive engagement in the IPTC means paying attention to the IPTC itself and comprehensively recognizing the IPTC from the perspective of Marxism. Once this occurs, the cultivation of college students' values and motivations can be strengthened. The IPTC has a far-reaching effect on soul cultivation and education among college students [17]. Only when college students have sufficient and comprehensive "cognition" of the IPTC can the actual meaning of the IPTC be achieved and thus further strengthen the development and innovation. Only by continuously enhancing college students' theoretical literacy and thinking ability and then directing them to establish a scientific worldview, methodology, and values can college students enhance their sense of gain [18]. First of all, college students must realize the importance of setting up the IPTC. From the perspective of our national strategy, the IPTC is an important course in terms of realizing the great goal of modernizing education, building a strong and well-educated country, and providing satisfactory education for the people [19]. To achieve democracy in this country as well as national prosperity and a peaceful work-life balance for the people, our citizens must first fundamentally understand this country and establish the ideal of working hard for the country. The IPTC is exactly intended to assume this responsibility and help the country prepare for the cultivation of builders and successors of the socialist cause. Secondly, college students should recognize the content of the different IPTC. Compared with other learning phases, the college IPTC is indeed different in terms of curriculum goal planning, curriculum system adjustment, curriculum content coordination, and textbook system compilation. Therefore, student engagement is critical to students' learning, especially in the IPTC. It is also necessary to highlight the characteristics of the course and to establish a dialectical Marxist worldview and methodology through theoretical study, in order to understand the world and then transform the world. Finally, college students should recognize how to practice the IPTC. In the classroom teaching of the IPTC, theoretical teaching is the main teaching form. However, relying solely on theoretical teaching is not nearly enough to make education effective, useful, and deeply rooted in the hearts of the people as the college classroom become more and more complex, and there are more interested parties [20]. Practical teaching is an important and useful supplement. This type of teaching is not only able to combine theory and practice, classroom and society, and learning and research but also helps students learn how to think and analyze, by linking theory with practice.

1.3. Cognitive Engagement Benefits Other Dimensions of Student Engagement in IPTC. In the course of IPTC teaching, paying attention to students' engagement can improve the effectiveness of IPTC as student engagement consists of cognitive engagement, affective engagement, conation engagement, and behavioral engagement. In this way, teachers can enhance these four aspects of engagement to jointly improve the overall student engagement level. Cognitive engagement of IPTC is college students' understanding and recognition of the rich content of IPTC. Affective engagement is the attitude of love and hate advocated and propagated by college students to the courses. Conation engagement helps college students to realize the responsibility and obligation given by society and take conscious and 
unremitting efforts. Behavioral engagement is the performance of the content of IPTC in action based on cognitive engagement, emotional engagement, and conation engagement. In this process, the four dimensions of engagement seem to be relatively independent, but it is an integration process of mutual connection, mutual influence, mutual penetration, and mutual promotion. Among them, cognitive engagement is the foundation, which guides, controls, and regulates emotional input, conation engagement, and behavioral engagement. In IPTC teaching, students' engagement can generally be carried out in the order of improving cognitive engagement, cultivating emotional engagement, exercising mental engagement, and practicing behavior engagement. Because there is no rule about which dimension comes first and which is last, it is acceptable for all four dimensions to proceed sequentially or in leaps. Through cognitive engagement of IPTC, college students enhance the cultivation of noble sentiment, cultivate strong revolutionary will behavior, and have stronger expressive force, indicating that cognitive engagement is more important.

\section{Methods}

2.1. Sample Collection and Investigation Process. By referring to many research questionnaires in the field of students' cognitive engagement [21-25], this study formed the $\mathrm{Na}$ tional Survey of Student Engagement in Ideological and Political Theory Course (NSSE-IPTC), allowing us to carry out research on college students' cognitive engagement with the IPTC. The cognitive engagement scale is a subscale of the Student Engagement Scale. When using the scale, students participating in this study were required to give different scores, according to their degree of agreement with each question. From disagreement to agreement, there are 1 to 10 points, respectively. The range of scores indicates the different degrees of cognitive engagement in processing information and answering questions.

Forty-seven universities were randomly sampled nationwide. Through open questionnaires, the cognitive engagement of different groups of students learned that the IPTC was investigated. The issuance of the questionnaire took into account multiple factors, such as region and school category. A total of 4700 questionnaires were actually distributed, and 4331 were recovered. After invalid questionnaires and incomplete waste papers were manually removed, 4115 valid questionnaires were recovered. After the data were input into the statistical software in the later period, another 123 nonconforming questionnaires were filtered out by high and low score grouping. Finally, 3992 questionnaires were available to be tested, so the effective rate of the questionnaire scale was $84.94 \%$. The questionnaire was analyzed statistically with the help of Epidata and SPSS17.0 statistical software. The composition of the subject group is shown in Table 1.

As can be seen from Table 1, the following information was explained:

(1) Gender. The gender ratio of male and female students was $53 \%$ and $47 \%$, respectively, and the
TABle 1: Participant composition frequency statistics.

\begin{tabular}{|c|c|c|}
\hline & Frequency & Percentage \\
\hline \multicolumn{3}{|l|}{ Gender } \\
\hline Male & 2115 & 53 \\
\hline Female & 1877 & 47 \\
\hline \multicolumn{3}{|l|}{ Nationality } \\
\hline Han & 3940 & 98.7 \\
\hline Other & 52 & 1.3 \\
\hline \multicolumn{3}{|l|}{ Student position } \\
\hline Classroom cadre & 471 & 11.8 \\
\hline Student union cadre & 40 & 1 \\
\hline Other & 3481 & 87.2 \\
\hline \multicolumn{3}{|l|}{ University type } \\
\hline Project 985 University & 1021 & 25.6 \\
\hline Project 211 University & 866 & 21.7 \\
\hline Non-985 and non-211 project university & 2019 & 50.6 \\
\hline Third batch of undergraduate & 86 & 2 \\
\hline \multicolumn{3}{|l|}{ Student grade } \\
\hline Freshman & 702 & 17.6 \\
\hline Sophomore & 1393 & 34.9 \\
\hline Junior & 1672 & 41.9 \\
\hline Senior & 225 & 5.6 \\
\hline Other & 0 & 0 \\
\hline \multicolumn{3}{|l|}{ Major } \\
\hline Liberal arts & 1588 & 39.8 \\
\hline Science & 2404 & 60.2 \\
\hline \multicolumn{3}{|l|}{ Family } \\
\hline Only child & 1449 & 36.3 \\
\hline Nononly child & 2543 & 63.7 \\
\hline \multicolumn{3}{|l|}{ Join clubs } \\
\hline Participation & 846 & 21.2 \\
\hline No participation & 3146 & 78.8 \\
\hline \multicolumn{3}{|l|}{ Religious } \\
\hline None & 3864 & 96.8 \\
\hline Buddhism & 64 & 1.6 \\
\hline Christianity & 43 & 1.1 \\
\hline Catholicism & 21 & 0.5 \\
\hline \multicolumn{3}{|l|}{ Mother's occupation } \\
\hline National party and Mass organization & 527 & 13.2 \\
\hline Technical staff & 317 & 7.9 \\
\hline Clerk & 842 & 21.1 \\
\hline Business and service industries & 385 & 9.6 \\
\hline $\begin{array}{l}\text { Agriculture, forestry, animal husbandry, } \\
\text { etc. }\end{array}$ & 317 & 7.9 \\
\hline Other & 1604 & 40.3 \\
\hline \multicolumn{3}{|l|}{ Father's occupation } \\
\hline National party and Mass organization & 83 & 2.0 \\
\hline Technical staff & 617 & 15 \\
\hline Clerk & 370 & 9.0 \\
\hline Business and service industries & 623 & 15.1 \\
\hline $\begin{array}{l}\text { Agriculture, forestry, animal husbandry, } \\
\text { etc. }\end{array}$ & 286 & 7.0 \\
\hline Other & 2013 & 51.9 \\
\hline
\end{tabular}

gender distribution was basically balanced. There is no uneven proportion distribution caused by departments, majors, and other reasons, so as to reduce the potential error as much as possible and ensure that the measurement results are not different due to gender differences. 
(2) Major. In the survey, 1588 valid scales were from liberal arts students, accounting for $39.8 \%$ of the total number of surveys. Science students had 2,404 questionnaires, accounting for $60.2 \%$. The majority of respondents were science students.

(3) Nationality. This study does not deliberately consider the proportion of ethnic minority students in IPTC, so the nationality of Han students accounts for $98.7 \%$, while other ethnic groups only account for $1.3 \%$. The reason is that most of the scales are distributed by the researcher's teachers, classmates, and friends, all of whom are from the Han nationality. As a result, the scales distributed to Han students account for a large proportion in the process of information collection, so that the scales do not pay special attention to the differences of ethnic minorities.

(4) Family Members. Since the subjects were post-1995 undergraduate students, the only one-child accounted for $36.3 \%$, while other families with two or more kids accounted for $63.7 \%$.

(5) Student Positions. In the survey, there were 471 student leaders, accounting for $11.8 \%$ of the surveyed students. Student union members are relatively small, 40 undergraduates, accounting for $1 \%$. $87.2 \%$ did not hold the position of student position.

(6) Join Clubs. Of the respondents, $21.2 \%$ of students said they had participated in school clubs, while $78.8 \%$ had not.

(7) University Type. A total of twelve "985 universities," ten "211 universities," other 24 universities, and 1 tertiary university were investigated. In the study, 22 universities were included in the "double Firstclass," accounting for $47.3 \%$ of the subjects. The uniform distribution at the college level has achieved the sampling effect.

(8) Religious. $3.2 \%$ of college students have religious beliefs, among which $1.6 \%$ are Buddhism and $1.1 \%$ are Christianity, and only $0.5 \%$ are Catholicism. Other college students are not involved.

(9) Grade of Students. In the sampling, the factor of college students' grades is considered, because the IPTC has different contents in different grades. But there is an exception that some students finish IPTC in other grades because of other factors such as retaking and suspension. Every subject of IPTC is in a unity and unified set. Only when all courses are completed completely by students can the overall education and teaching effect be shown.

(10) Parents' Occupation. According to the research, $59.7 \%$ of college students expressed their mothers' occupation while $40.3 \%$ did not specify their mothers' occupation. Accordingly, $48.1 \%$ of the college students made a specific distinction about their father's occupation while $51.9 \%$ of the other students did not explain their father's occupation.
2.2. Reliability and Validity Test. This research uses Cronbach's alpha to test the reliability of the scale indicators. The degree of intersection refers to the degree of accuracy of the measurement result, that is, the degree of closeness between the measurement result and the object to be measured. The higher the correlation coefficient, the better the criteria of the questionnaire. From Table 2, Cronbach's alpha of college students' cognitive engagement in IPTC is 0.759 , which performs well, thereby indicating that the scale has high credibility and is suitable for the factor analysis. A correlation analysis is to determine the statistical correlation between two or more variables. Then, the strength and direction of the correlation must be analyzed.

\section{Optimization Model Analysis}

\subsection{Factor Analysis}

3.1.1. The Basic Principle of Factor Analysis. When C. Sparman put forward factor analysis, it has been widely used in many fields [26]. That is, through the correlation study of many variables, many original variables are condensed into a few imaginary factor variables, so that these factor variables have stronger analytical power. The general model of factor analysis is as follows:

$$
\left\{\begin{array}{l}
X_{1}=a_{11} F_{1}+a_{12} F_{2}+\cdots+a_{1 m} F_{m}+\varepsilon_{1} \\
X_{2}=a_{21} F_{1}+a_{22} F_{2}+\cdots+a_{2 m} F_{m}+\varepsilon_{2} \\
\cdots \\
X_{p}=a_{p 1} F_{1}+a_{p 2} F_{2}+\cdots+a_{p m} F_{m}+\varepsilon_{p} .
\end{array}\right.
$$

$X_{1}, X_{2}, \ldots, X_{p}$ is the measured variable; $a_{i j}(i=1,2, \ldots, p ; j=1,2, \ldots, m)$ is the factor load; $F_{j}(j=$ $1,2, \ldots, m)$ is the common factor; $\varepsilon_{i}(i=1,2, \ldots, p)$ is a special factor. In the case that each factor is not correlated, the factor $l o a d a_{i j}$ is the correlation factor between the $i$ original variable and the $j$ factor variable, that is, the relative importance of $X_{i}$ on the $j$ common factor variable. Therefore, the larger the load is, the closer the relationship between the $i$ variable and the $j$ factor is. The smaller the load is, the more distant the relationship between the $i$ variable and the $j$ factor is. In high-dimensional space, they are mutually perpendicular coordinate axes. However, the special factor is actually the residual between the measured variable and the estimated value. If the special factor is zero, the principal component analysis is performed. In order to make the principal factors found easier to explain, it is often necessary to rotate the factor loading matrix, and the most commonly used rotation method is the maximum variance rotation method Varimax. The purpose of factor rotation is to differentiate the square value of factor load in the factor load matrix toward 0 and 1, so that the large load is bigger and the small load is smaller. Therefore, factor scores need to be calculated. Since the common factor can reflect the relevant information of the original variable, it is sometimes more beneficial to describe the characteristics of the research object when the common factor is used to represent the original variable. Therefore, it is often necessary to express 
TABLE 2: Reliability statistics.

\begin{tabular}{lc}
\hline Cronbach's alpha & No. of items \\
\hline 0.759 & 14
\end{tabular}

the common factor as a linear combination of variables (or samples) in reverse, namely,

$$
F_{j}=\beta_{j 1} X_{1}+\beta_{j 2} X_{2}+\cdots+\beta_{j p} X_{p} ; \quad j=1,2, \ldots, m .
$$

Factor scoring function (2) is used to calculate the common factor score for each sample. Since the number of equations $m$ is less than the number of variables $p$ in the factor score function, the factor score cannot be calculated accurately, and only the factor score can be estimated. The usual estimation methods include the weighted least square method and regression method.

3.1.2. KMO and Bartlett Sphere Test. A Kaiser-Meyer-Olkin (KMO) test is used in research to determine the sampling adequacy of data that are to be used for factor analysis. Social scientists often use factor analysis to ensure that the variables they have used to measure a particular concept are measuring the concept intended [27]. The KMO test shows the data are suitable to run a factor analysis and therefore determine whether we have set out and what we intended to measure. Before conducting factor analysis, a KMO and Bartlett sphere test was performed. As shown in Table 3, the KMO value of the cognitive engagement scale for IPTC is 0.703 (greater than 0.5). This finding indicates that the variables have a strong correlation, and the data are suitable for factor analysis.

\subsubsection{Principal Component Extraction and Factor Rotation.} Suppose random variables $X=\left\{X_{1}, X_{2}, \ldots, X_{p}\right\}$, the normalized variable $x=\left\{x_{1}, x_{2}, \ldots, x_{p}\right\}$, its correlation matrix $R=\left(r_{-} i j\right)$, its $k(k \leq p)$, and nonzero characteristic roots are $\lambda_{1}, \lambda_{2}, \ldots, \lambda_{k}$. The corresponding eigenvector is $l_{i j}$; then, the principal component estimation of the factor load of the $j$ factor $F_{j}$ is the product of the square root of the corresponding Eigen root and the corresponding eigenvector:

$$
a_{i j} l_{i j} \sqrt{\lambda_{j}}, \quad i=1,2, \ldots, j=1,2, \ldots, k .
$$

Factor load is the correlation coefficient between the common factor and index variable. The larger the load is, the closer the relationship between the common factor and index variable is. When determining the number of common factors, the number of factors equal to the number of original variables is first selected, the total variance of factors is calculated, and then, the factor whose eigenvalue is greater than 1 after rotation is taken as the common factor. Therefore, the change of six common factors of principal components after dimensionality reduction is selected to describe the change of the original index set.

3.1.4. Calculated Factor Score. Since the index variable $X$ meets the orthogonal factor model, the common factor $F$ can also be expressed as a linear combination of variable $X$, from which the model can calculate the comprehensive evaluation value, ranking the evaluation value from large to small, and ranking the cognitive input factors from high to low that can be given.

For cognitive engagement, there are only 6 equations and 14 variables, so it can only be estimated in the sense of least squares. The regression method is used to calculate the scores of factors $F_{1}, F_{2}, F_{3}, F_{4}, F_{5}$, and $F_{6}$, and the comprehensive score of each factor $Q_{t}$ is shown in

$$
Q_{t}=\frac{\sum_{i=1}^{33} \lambda_{i} F_{i}}{\sum_{i=1}^{33} \lambda_{i}}, \quad t=X_{1}, X_{2}, X_{3}, \ldots, X_{13}, X_{14} .
$$

From formula (4), where $\lambda_{i}$ is the eigenvalue corresponding to the correlation matrix of $X$, after several repetitions of the exploratory factor analysis on the scale, the total variance table explained by the factor components was obtained through the principal component analysis method [28].

As shown in Table 4, when the second component is reached, the 14 questions can explain $45.459 \%$ of the total variation. Also, six factors with an eigenvalue of greater than 1 can be determined, so the six common factors should be extracted. According to the component factors of the rotate on matrix, the first factor contains questions 2 and 12, the second factor contains questions 3 and 5, the third factor contains questions 13 and 14, the fourth factor contains questions 7 and 11, the fifth factor contains questions 6 and 9 , and the sixth factor contains questions 4 and 10.

As can be seen from Figure 1, the eigenvalues of the first six factors are all greater than 1 , and the inflection point appears from the seventh factor. Therefore, the first six factors were selected. According to the characteristics of college students, by combining literature with questionnaire items, a reasonable factor analysis of college students' cognitive engagement in IPTC was formed.

As shown in Table 5, there are six important factor dimensions affecting college students' cognitive engagement in the IPTC, namely, attention and motivation factor dimension, behavior and value attainment factor dimension, interest and practicality factor dimension, personality and will factor dimension, evaluation and time factor dimension, and knowledge and strategy factor dimension.

3.2. Descriptive Analysis of College Students' Cognitive Engagement. Descriptive statistics is a method of sorting out and analyzing data through graphs or mathematical methods and then estimating and describing the relationship between data distribution, digital features, and random variables[29]. Through descriptive statistics, the minimum and maximum estimates are solved; the other data are outliers. However, a logical outlier can be retained if it actually exists.

As shown in Table 6, for the attention and motivation dimension, the maximum value is 10 , the minimum value is 4 , and the mean value is 6.4701 . For the behavior and value attainment dimension, the maximum value is 10 , the minimum value is 4 , and the mean value is 6.5153 . For the 
TABLE 3: KMO and Bartlett sphere test.

\begin{tabular}{lcc}
\hline KMO sampling appropriateness measurement & & \\
\hline Bartlett sphere test & Approximate chi-square & 0.703 \\
& Degrees of freedom & 97.947 \\
& Significance & 91 \\
\hline
\end{tabular}

TABLE 4: Explanation of the total variance of students' cognitive engagement in IPTC.

\begin{tabular}{|c|c|c|c|c|c|c|c|}
\hline \multicolumn{4}{|c|}{ Initial eigenvalue } & \multicolumn{3}{|c|}{ Extraction sums of squared loadings } & \multirow{2}{*}{$\begin{array}{c}\text { Rotation sums of } \\
\text { squared loadings } \\
\text { Total }\end{array}$} \\
\hline Component & Total & Variance percentage & Cumulative (\%) & Total & Variance percentage & Cumulative (\%) & \\
\hline$X_{1}$ & 1.109 & 7.919 & 7.919 & 1.109 & 7.919 & 7.919 & 1.082 \\
\hline$X_{2}$ & 1.081 & 7.725 & 15.643 & 1.081 & 7.725 & 15.643 & 1.071 \\
\hline$X_{3}$ & 1.059 & 7.567 & 23.211 & 1.059 & 7.567 & 23.211 & 1.061 \\
\hline$X_{4}$ & 1.053 & 7.522 & 30.733 & 1.053 & 7.522 & 30.733 & 1.059 \\
\hline$X_{5}$ & 1.041 & 7.436 & 38.169 & 1.041 & 7.436 & 38.169 & 1.048 \\
\hline$X_{6}$ & 1.021 & 7.290 & 45.459 & 1.021 & 7.290 & 45.459 & 1.043 \\
\hline$X_{7}$ & 0.996 & 7.117 & 52.576 & & & & \\
\hline$X_{8}$ & 0.988 & 7.056 & 59.632 & & & & \\
\hline$X_{9}^{\circ}$ & 0.978 & 6.984 & 66.616 & & & & \\
\hline$X_{10}$ & 0.961 & 6.865 & 73.481 & & & & \\
\hline$X_{11}$ & 0.946 & 6.757 & 80.238 & & & & \\
\hline$X_{12}$ & 0.934 & 6.672 & 86.910 & & & & \\
\hline$X_{13}$ & 0.929 & 6.633 & 93.544 & & & & \\
\hline$X_{14}$ & 0.904 & 6.456 & 100.000 & & & & \\
\hline
\end{tabular}

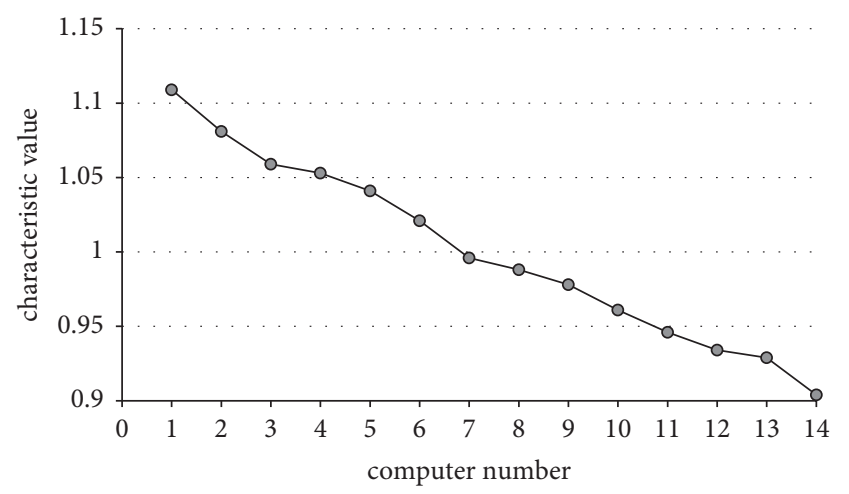

Figure 1: Gravel figure of effect factor.

interest and practicality dimension, the maximum value is 10 , the minimum value is 4 , and the mean value is 6.5435 . For personality and will dimension, the maximum value is 10 , the minimum value is 4 , and the mean value is 6.5837 . For evaluation and time dimension, the maximum value is 10 , the minimum value is 4 , and the mean value is 6.4696 . For the knowledge and strategy dimension, the maximum value is 10 , the minimum value is 4 , and the mean value is 6.3505. This set of data shows no abnormal values, and all the mean values are between the minimum and maximum values. The scores of attention and motivation dimension, behavior and value attainment dimension, interest and practicality dimension, personality and will dimension, evaluation and time dimension, and knowledge strategy factor dimension are all greater than 6, indicating good overall evaluation. "Personality and will dimension" has the highest score $(M=6.5837)$, while the knowledge and motivation factor dimension has the joint lowest score
$(M=6.3505)$. This finding indicates that personality and will dimension plays a relatively major role among the factors influencing college students' cognitive engagement in IPTC, while the knowledge motivation dimension has a weak impact on cognitive engagement.

3.3. Linear Regression Analysis of College Students' Cognitive Engagement. A Pearson's correlation coefficient can be used to measure the correlation between two fixed distance and fixed ratio variables, which is a parametric test [30]. From Table 7, one can see that the correlation is significant at 0.01 level (twotailed) and the correlation is significant at the 0.05 level (twotailed), which means that there is a significant positive correlation exists between cognitive engagement and other variables according to Pearson. The attention and motivation factor dimension, behavior and value attainment factor dimension, interest and practicality factor dimension, personality and will factor dimension, evaluation and time factor dimension, and knowledge and strategy factor dimension are all correlated with each other, which mean that the scale has structural validity. Through the correlation test, one can understand the correlation between the factors that influence cognitive engagement.

A linear regression analysis is a method used to study the influence relationship. The essence of such an analysis is to study the impact of one or more independent variables $X$ on a dependent variable $Y$ (quantitative data) [31]. A regression analysis is made on the basis of a correlation analysis and is used to study whether an influence relationship exists because a correlation may exist sometimes; there is not necessarily a regression influence relationship. As can be seen from Table $8, R^{2}=0.719, F=1699.351$, and $P \leq 0.001$. This indicates that attention and motivation dimension, behavior 
TABLE 5: Factors influencing college students' cognitive engagement in IPTC.

\begin{tabular}{|c|c|c|c|c|c|c|c|}
\hline \multirow[b]{2}{*}{ Item } & \multirow[b]{2}{*}{ Index } & \multicolumn{6}{|c|}{ Factor naming } \\
\hline & & $\begin{array}{l}\text { Attention and } \\
\text { motivation factor }\end{array}$ & $\begin{array}{c}\text { Behavior and } \\
\text { value attainment }\end{array}$ & $\begin{array}{c}\text { Interest and } \\
\text { practical factors }\end{array}$ & $\begin{array}{c}\text { Personality and } \\
\text { will factors }\end{array}$ & $\begin{array}{l}\text { Evaluation and } \\
\text { time factor }\end{array}$ & $\begin{array}{l}\text { Knowledge and } \\
\text { strategic factors }\end{array}$ \\
\hline$\overline{X_{1}}$ & Attitude & & & & & & \\
\hline$X_{2}$ & Attention & 0.473 & & & & & \\
\hline$X_{3}$ & $\begin{array}{c}\text { Value } \\
\text { attainment }\end{array}$ & & 0.444 & & & & \\
\hline$X_{4}$ & $\begin{array}{l}\text { Knowledge } \\
\text { acquisition }\end{array}$ & & & & & & 0.574 \\
\hline$X_{5}$ & Behavior gain & & 0.43 & & & & \\
\hline$X_{6}$ & $\begin{array}{c}\text { Teacher } \\
\text { evaluation }\end{array}$ & & & & & 0.441 & \\
\hline$X_{7}$ & Personality & & & & 0.51 & & \\
\hline$X_{8}$ & Learning plan & & & & & & \\
\hline$X_{9}$ & Learning time & & & & & 0.405 & \\
\hline$X_{10}$ & $\begin{array}{l}\text { Learning } \\
\text { strategy }\end{array}$ & & & & & & 0.414 \\
\hline$X_{11}$ & Will & & & & 0.484 & & \\
\hline$X_{12}$ & Motivation & 0.407 & & & & & \\
\hline$X_{13}^{12}$ & Interest & & & 0.488 & & & \\
\hline$X_{14}^{13}$ & Practicality & & & 0.629 & & & \\
\hline
\end{tabular}

TABLE 6: Descriptive statistics of college students' cognitive engagement.

\begin{tabular}{lccccc}
\hline & $N$ & Minimum & Maximum & Mean & Standard deviation \\
\hline Attention and motivation & 3992 & 4.00 & 10.00 & 6.4701 & 1.17031 \\
Behavior and value attainment & 3992 & 4.00 & 10.00 & 6.5153 & 1.04270 \\
Interest and practicality & 3992 & 4.00 & 10.00 & 6.5435 & 1.24626 \\
Personality and will & 3992 & 4.00 & 10.00 & 6.5837 & 1.19115 \\
Evaluation and time & 3992 & 4.00 & 10.00 & 6.4696 & 1.23148 \\
Knowledge and strategy & 3992 & 4.00 & 10.00 & 6.3505 & 1.18869 \\
Number of valid cases (in a row) & 3992 & & & & \\
\hline
\end{tabular}

TABLE 7: Correlation of college students' cognitive engagement.

\begin{tabular}{lccccccc}
\hline & $\begin{array}{c}\text { Cognitive } \\
\text { engagement }\end{array}$ & $\begin{array}{c}\text { Attention and } \\
\text { motivation }\end{array}$ & $\begin{array}{c}\text { Behavior and } \\
\text { value } \\
\text { attainment }\end{array}$ & $\begin{array}{c}\text { Interest and } \\
\text { practicality }\end{array}$ & $\begin{array}{c}\text { Personality } \\
\text { and will }\end{array}$ & $\begin{array}{c}\text { Evaluation } \\
\text { and time }\end{array}$ & $\begin{array}{c}\text { Knowledge } \\
\text { and strategy }\end{array}$ \\
\hline $\begin{array}{l}\text { Cognitive } \\
\text { engagement }\end{array}$ & $\begin{array}{c}\text { Pearson } \\
\text { correlation } \\
\text { Sig. (Two- } \\
\text { tailed) }\end{array}$ & 1 & $0.328^{* *}$ & $0.323^{* *}$ & $0.412^{* *}$ & $0.380^{* *}$ & $0.369^{* *}$ \\
0 & .000 & .000 & .000 & .000 & .000 & .000 \\
\hline
\end{tabular}

${ }^{* *}$ At 0.01 level (two-tailed), the correlation is significant. *At the 0.05 level (two-tailed), the correlation is significant.

and value attainment dimension, interest and practicality dimension, personality and will dimension, evaluation and time dimension, and knowledge and strategy factor dimension all play a positive predictive role in college students' cognitive engagement. Of these factors, attention and motivation dimension has the highest influence weight (eigenvalue $=0.05$ ), while knowledge and strategy dimension has the lowest influence weight (eigenvalue $=0.01$ ).

\section{Discussion}

As seen from the statistical analysis, the following factors are important aspects that affect college students' cognitive engagement in IPTC.
4.1. Attention and Motivation Dimension. The relationships between the child-parent reading behaviors and the children's cognitive attainment were identified [32]. In the cognitive process of IPTC, both teachers' and students' cognition of attention are usually specific, sensible, and easiest to show. In teaching situations, attention is the first to be recognized and manifested. In a state of attention, a student's consciousness and psychological activities will be oriented to and focused on the learning content, in such a way that the consciousness content or object is clear and definite. The consciousness process is tense and orderly, and the individual's behavior and activities are finally controlled by consciousness. In the IPTC learning process, college students always differentiate their attention levels, 
TABLE 8: Linear analysis of cognitive engagement.

\begin{tabular}{|c|c|c|c|c|c|c|c|c|c|c|}
\hline & \multirow[t]{2}{*}{ Model } & \multicolumn{2}{|c|}{$\begin{array}{c}\text { Nonstandard } \\
\text { coefficient }\end{array}$} & \multirow{2}{*}{$\begin{array}{c}\text { Standard coefficient } \\
\text { Beta }\end{array}$} & \multirow[t]{2}{*}{$t$} & \multirow[t]{2}{*}{ Significance } & \multicolumn{2}{|c|}{$\begin{array}{c}\text { Collinearity } \\
\text { statistics }\end{array}$} & \multirow[t]{2}{*}{$R^{2}$} & \multirow[t]{2}{*}{$F$} \\
\hline & & $B$ & Standard error & & & & Eigenvalue & VIF & & \\
\hline \multirow{7}{*}{1} & (Constant) & 1.35 & 0.05 & & 26.68 & 0.00 & 6.84 & & & \\
\hline & Attention and motivation & 0.09 & 0.00 & 0.2 & 22.42 & 0.00 & 0.05 & 1.40 & & \\
\hline & Behavior and value attainment & 0.15 & 0.00 & 0.33 & 39.05 & 0.00 & 0.04 & 1.01 & 0.719 & 1699.351 \\
\hline & Interest and practicality & 0.15 & 0.00 & 0.40 & 47.84 & 0.00 & 0.03 & 1.00 & & \\
\hline & Personality and will & 0.15 & 0.00 & 0.37 & 44.33 & 0.00 & 0.03 & 1.00 & & \\
\hline & Evaluation and time & 0.15 & 0.00 & 0.39 & 46.18 & 0.00 & 0.02 & 1.00 & & \\
\hline & Knowledge and motivation & 0.10 & 0.00 & 0.25 & 25.09 & 0.00 & 0.01 & 1.40 & & \\
\hline
\end{tabular}

depending on the degree of effort and whether or not there is the presence of a learning purpose. If one tries to use vivid pictures to illustrate the scenes of major events, the virtues of historical figures, or the tragedy of war, using modern media technology to give students strong sensory stimulation and thereby attract their attention, the students will naturally positively participate in learning these things. Motivation is the power and thought that triggers a person to engage in certain behavior. Motivation directly refers to the special psychological state and willingness to meet various specific needs. It is the internal stimulation or power that directly drives an individual's activities. The IPTC has been implanted in the lives of college students for a long time, due to the course's particularities. College students are not unfamiliar with these particularities. Therefore, the pressure on these students is quite small, leading to weakened learning motivation. This is precisely why students' level of cognitive engagement in the IPTC is not high.

4.2. Behavior and Value Attainment Dimension. There are some observable aspects, for example, time-on-task, class participation, and completion of homework [33] related cognitive engagement. But, most of them are often extracted from teachers' observations of students' behavior in the classroom [34]. In fact, the IPTC is a discipline that teaches theories and expounds on the value of thought so that learners pursue the course in the spirit of truth-seeking. However, such ideological value is not a rootless duckweed but must be rooted in the vastness of real life and must be dissolved in the melting pot of the times, which makes the behavior and value attainment dimension extremely important. College students' overall perception of the value of the IPTC is relatively satisfactory. Almost all of the college students who participated in the survey have an accurate understanding of the importance of the IPTC, and they believe that the IPTC is important for their entire lives. However, there are also college students who weaken the value of the IPTC when making important choices in their lives, in such a way that the course fails to display unique value. That is, compared with skill-based courses, the IPTC is not effective in students' decision-making.

4.3. Interest and Practicality Dimension. It has been argued that if teachers and schools could support students' academic behavioral skills, they could benefit from the engagement and then increase students' academic performance [35], from which the interest and practicality of students are important facts. In their learning of the IPTC, college students currently pay more attention to the maintenance of individual interests. In the IPTC, one can better understand this structure by studying students' psychological engagement, their interests and learning strategies, and especially their learning strategies related to self-regulation. College students show a clear goal orientation toward the IPTC, which reflects a certain extent that they need to input their stable individual interests into the IPTC learning process. By doing so, they can pay more attention to the course and learn more deeply. In the learning process, students may develop a great interest in a certain discipline or a certain class, due to various factors, such as teachers and individual psychology. However, as factors like environmental change, such situational interest may partially or even completely disappear. In the end, as seen from the overall course acquisition process, college students' cognitive engagement is not high. Such unstable states exist in different colleges, different majors, and different groups. In view of this, the course's application should be strengthened, so that college students will not turn the IPTC into a course of memorizing knowledge points under the pressure of coping with exams. That approach will ignore the existence value of the IPTC and will also ignore the course's role in deep-seated value guidance for college students.

4.4. Personality and Willing Dimension. Personality is a general feature that an individual exhibits in the face of reallife situations. However, recent research has demonstrated that personality is not substantially correlated with cognitive ability [36]. Intellectual characteristics, on the other hand, are the main components of a psychological feature that an individual displays in cognitive activities. In the cognitive engagement in the IPTC, effectively guiding and utilizing the personality and will factor of college students is an important way to increase the effectiveness of the IPTC. It is not difficult to understand that, in IPTC classrooms, most teachers will use fascinating situational introduction methods to arouse college students' interest. The teachers analyze college students' personality characteristics based on the overall judgment of the class, and they display certain inspiration and clue guidance through their words when students raise questions and express opinions. In essence, 


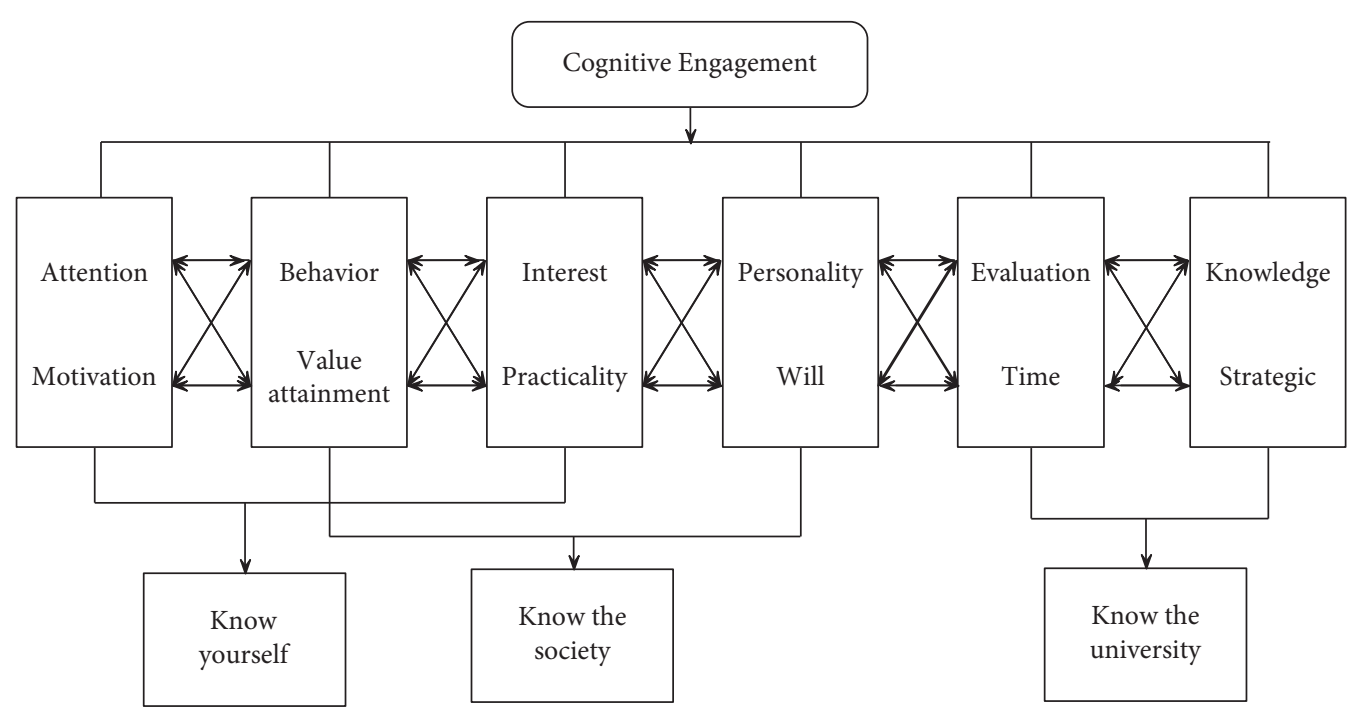

FIGURE 2: Important factors affecting cognitive engagement multidimensional optimization model.

teachers actively direct students to participate in the overall classroom organization from their aspects. This also means that teachers should discover and observe students' individual performance in learning materials in a timely manner. The teachers should use vivid language to give thinking space to those students who choose to listen and affectionate gazes to encourage students who are eloquent and willing to express and share their views.

4.5. Evaluation and Time Dimension. Recently, more and more students start their IPTC learning online, which has been explained to promote students engagement [37]. When the assessment of the IPTC is an important method to guide students to conscious learning, it may stimulate their enthusiasm for learning. However, the traditional ideological and political education evaluation model focuses on assessing students' theoretical knowledge. This model reduces college students' interest in learning ideological and political education courses and fails to comprehensively evaluate students' actual ideological and political consciousness. Optimizing the course assessment system and giving scientific student evaluations would inevitably improve the traditional evaluation model of ideological and political education; this approach would also construct a new, diversified threedimensional evaluation model. With the rapid development of our society, social wealth has increased dramatically and people's lives have become more prosperous. Nonetheless, it is undeniable that some social phenomena have also existed (and even worsened) in our society during this transition period, such as the gap between the rich and the poor, social injustice, extravagance, and waste. The contradictions reflected in these phenomena are very inconsistent with the values and social civilization advocated by the IPTC. The impact on some college students will arouse irrational cognition, causing these students to become ambivalent and unwilling to invest their time and energy in the IPTC learning. Also, this situation will put the study of the IPTC in an awkward position.
4.6. Knowledge and Strategy Dimension. Strategies could help optimize the work environment in terms of affordable job demands and sufficient job resources as well as increase personal resources, such as optimism, self-efficacy, and selfesteem [38]. Subsequently, in the cognitive engagement of the IPTC, political, ideological, academic, and professional nature must be closely linked. Such a theoretical and highly professional curriculum will inevitably involve the influence of learning strategies, which will create an interactive influence between college students and teachers, students and learning content, and among students themselves. Research has demonstrated that the course could strongly support students in training interest and the role of self-efficacy for the course of study for task experiences and knowledge development [39]. In the process of cognitive engagement, teachers must actively adopt teaching strategies, while students should respond with active learning strategies. All parties should make their own adjustments, expand their thinking, and flexibly use autonomous learning strategies and goal-oriented strategies.

\section{Conclusions}

Through the investigation and statistical analysis of this research, the following conclusions can be drawn:

(1) The six fact dimensions affect college students' cognitive engagement. Although college students' cognition can be measured in different ways, compared with emotional and behavioral engagement, cognitive engagement is not so easily observed and captured; cognitive engagement is actually relatively hidden. Among the six multidimensional factors through principal component analysis and factor analysis methods, attention and motivation dimension, behavior and value attainment dimension, interest and practicality dimension, personality and will dimension, evaluation and time dimension, and knowledge and strategy dimension are important 
factors that influence college students' participation in the learning process of the IPTC. College students lack motivation in IPTC learning. Some students show a helpless state in their studies; they are unwilling to devote their time and energy to learning, and they lack understanding of the learning process. College students have insufficient cognitive engagement and motivation in the subject. Some college students attach great importance to the beneficial value of the course, and these students focus on the benefits that the course brings to them. If the course has many benefits, the enthusiasm for learning is strong; otherwise, the enthusiasm is not high. Such serious individualism and utilitarianism exist.

(2) Through the descriptive statistical analysis method, the scores of the six factor dimensions are all greater than 6, indicating there is good overall evaluation, in which the score of "personality and will dimension" is the highest $(M=6.5837)$ and the score of "knowledge and motivation dimension" is the lowest $(M=6.3505)$. This finding indicates that the "personality and will dimension" plays a relatively important role among the factors influencing college students' cognitive engagement in IPTC, while the "knowledge and motivation dimension" has a weak impact on cognitive engagement. Teacher self-efficacy predicted later work satisfaction via engagement and their initial work satisfaction predicted later teacher self-efficacy via engagement too [40]. Compared with teachers' self-efficacy beliefs, engagement, and satisfaction directly and indirectly, the degree of college students' cognitive engagement in the IPTC also determines the different senses of self-efficacy. For example, the motivation dimension scores of learning engagement are significantly higher among students of "Project 985" and "Project 211" universities than those of ordinary colleges. At the same time, the scores of some "non-985" and "non211 " universities in this aspect are significantly lower than those of "Project 985" and "Project 211" universities. The key majors of some colleges and universities have also affected students' cognitive engagement. Students with a strong sense of professional superiority have a higher degree of recognition toward the IPTC, and vice versa. During the learning process of the IPTC, some students have relatively low expectations of learning, which also leads to a lower sense of self-efficacy. When it comes to choosing learning tasks and making learning plans, most students can arrange their time to learn the most important content first. Meanwhile, some students will skip the difficult content and only master the content within their capability, leading to different senses of information interaction efficacy among students. Those with a high overall evaluation of ideological and political learning activities will, overall, have a higher sense of efficacy in learning.
(3) Through correlation analysis and linear regression analysis, there is a significant positive correlation between cognitive engagement and other variables, and the data $R^{2}=0.719, F=1699.351$, and $P \leq 0.001$ show that the six variables play a positive role in college students' cognitive engagement. Factors such as grade, status, and social experience will affect students' cognitive engagement in the IPTC. As far as grades are concerned, senior students have superior cognition and identification than those of lower grades. In terms of identity, student party members and student cadres have significantly superior cognition and identification than ordinary students. In terms of social experience, students with rich experience in social practices have superior cognition and identification than students who do not participate in social practices. The reasons behind these findings are worth reflection. In addition, in the cognitive engagement of the IPTC, individual goals do not play a sufficient role in the course; the learners' goals typically depend on whether they believe they can change the status.

(4) A multidimensional optimization model of important factors affecting college students' cognitive engagement in IPTC has been built.

From Figure 2, one can see that a multidimensional optimization model on important factors affecting cognitive engagement has been built in the paper. To improve the effectiveness of the IPTC and enhance college students' sense of acquisition in the IPTC in terms of both future education and teaching, teachers should adopt various effective ways to continuously strengthen and reinforce college students' cognitive engagement in the IPTC. Most important, teachers and universes should let college students know themselves and society. In this way, the uniqueness of the IPTC should be reflected, and the basic principles of Marxism should be used to arm college students' thinking. There is a necessity to combine students' cognitive feelings with the learned contents in a timely manner so as to achieve ideological enlightenment and guidance and to enable methodological improvement. In this way, one can increase college students' learning initiative and enthusiasm, integrate relevant educational resources, and make the IPTC a course that directly hits the hearts of college students and truly displays the effect of soul cultivation and education.

\section{Data Availability}

The data used to support the findings of this study are included within the article.

\section{Conflicts of Interest}

The author does not have any possible conflicts of interest.

\section{Acknowledgments}

This work was supported by the Shaanxi Association of Higher Education 2019 Higher Education Scientific 
Research Project (XGH19080) and Northwestern Polytechnical University Degree and Graduate Education Research Fund Project (2019-2020). Also, the author would like to sincerely thank and appreciate Prof. Mingfang Fan for his suggestions and encouragement.

\section{References}

[1] Z. Su, "Casting soul and Educating people: the lifeline of ideological and political theory teaching," Studies in Ideological Education, vol. 320, no. 2, pp. 8-13, 2021.

[2] S. Huang, Y. Wei, and B. Li, "Three dimensions to strengthen the construction of ideological and political theory course in the new era," Leading Journal of Ideological \& Theoretical Education, vol. 1, pp. 109-112, 2020.

[3] M. Harvey and I. Solomonides, "Peer review in a foundations in learning and teaching program," in Peer Review of Learning and Teaching in Higher Education. Professional Learning and Development in Schools and Higher Education, J. Sachs and M. Parsell, Eds., vol. 9, pp. 137-149, Springer, Dordrecht, Netherlands, 2014.

[4] V. Tinto, Leaving College Rethinking the Causes and Cures of Student Attrition, University of Chicago Press, Chicago, 2nd edition, 1993.

[5] A. W. Astin, "Student involvement: a developmental theory for higher education," Journal of College Student Personnel, vol. 99, no. 40, pp. 297-308, 1984.

[6] S. L. Christenson, A. L. Reschly, J. J. Appleton, S. Berman, D. Spanjers, and P. Varro, Best Practices in School Psychologypp. 45-57, National Association of School Psychologists, MD, USA, 5th edition, 2008.

[7] D. Marcia, "Measuring student engagement in the online course: the online student engagement scale (OSE)," Online Learning, vol. 19, no. 4, 2015.

[8] L. Corno and E. B. Mandinach, "The role of cognitive engagement in classroom learning and motivation," Educational Psychologist, vol. 18, no. 2, pp. 88-108, 1983.

[9] J. P. Connell and J. G. Wellborn, "Competence, autonomy, and relatedness: a motivational analysis of self-system processes," in Proceedings of the Minnesota Symposium On Child Psychology, pp. 23-36, University of Chicago Press, Hillsdale, MI, USA, October 1991.

[10] F. Newmann, G. G. Wehlage, and S. D. Lamborn, "The significance and sources of student engagement," Student Engagement and Achievement in American Secondary Schools, pp. 11-39, Teachers College Press, NY, USA, 1992.

[11] G. G. Wehlage, R. R. A. Rutte, G. A. Smith, N. L. Lesko, and R. R. Fernandez, Reducing the Risk: Schools as Communities of Support, pp. 78-114, Farmer Press, Philadelphia, PA, USA, 1989.

[12] P. R. Pintrich and E. V. De Groot, "Motivational and selfregulated learning components of classroom academic performance," Journal of Educational Psychology, vol. 82, no. 1, pp. 33-40, 1990.

[13] B. J. Zimmerman, "Self-regulated learning and academic achievement: an overview," Educational Psychologist, vol. 21, pp. 3-17, 1993.

[14] L. Corno, "The best-laid plans," Educational Researcher, vol. 22, no. 2, pp. 14-22, 1993.

[15] J. D. Finn, J. Folger, and D. Cox, "Measuring participation among elementary grade students," Educational and Psychological Measurement, vol. 51, no. 2, pp. 393-402, 1991.
[16] J. I. Rotgans and H. G. Schmidt, "Cognitive engagement in the problem-based learning classroom," Advances in Health Sciences Education, vol. 16, no. 4, pp. 465-479, 2011.

[17] G. Xiao, "On the institutionalization of ideological and political theory course in the New Era," Leading Journal of Ideological \& Theoretical Education, vol. 4, pp. 98-104, 2021.

[18] L. Zhang, "Ideological and political theory course: the main channel of 'Three Views'education," Social Sciences in Chinese Higher Education Institutions, vol. 1, pp. 42-46, 2007.

[19] Z. Xie and Y. Shao, "The practice teaching of ideological and political course cultivates the system self-confidence of college students," The Party Building and Ideological Education in Schools, vol. 8, pp. 50-52, 2021.

[20] L. Wang, M. Fan, and F. Zhang, "Applying fuzzy fault tree method to evaluate the reliability of college classroom," Front. Psychol.- Educational Psychology, vol. 12, Article ID 593068, 2021.

[21] J. D. Finn and K. S. Zimmer, "Student Engagement: What Is it? Why Does it Matter?" Handbook Of Research on Student Engagement, Springer, NY, USA, pp. 97-131, 2012.

[22] J. J. Appleton, S. L. Christenson, D. Kim, and A. L. Reschly, "Measuring cognitive and psychological engagement: validation of the student engagement instrument," Journal of School Psychology, vol. 44, no. 5, pp. 427-445, 2006.

[23] C. R. Pace, Measuring Outcomes of College: Fifty Years of Findings and Recommendations for the Future, Jossey-Bass, San Francisco, CA, USA, 1979.

[24] C. Derouesné, C. Dealberto, M. J. Boyer, P. Lubin, and S. Sauron, "Empirical evaluation of the 'Cognitive Difficulties Scale' for assessment of memory complaints in general practice: a study of 1628 cognitively normal subjects aged 45-75 years," International Journal of Geriatric Psychiatry, vol. 8, no. 7, pp. 599-607, 1993.

[25] M. Csikzentmihalyi, "The flow experience and its significance for human psychology," Optimal Experience, pp. 15-35, Cambridge University Press, Cambridge, UK, 1998.

[26] R. J. Sternberg, "The geographic metaphor," in Metaphors of Mind: Conceptions of the Nature of Intelligence, R. J. Sternberg, Ed., pp. 85-111, NY: Cambridge, 1990.

[27] B. A. Cerny and H. F. Kaiser, "A study of a measure of sampling adequacy for factor-analytic correlation matrices," Multivariate Behavioral Research, vol. 12, no. 1, pp. 43-47, 1977.

[28] M. Awang, B. Singh, and I. Dzulkarnain, "An analysis of the relationship between effective teaching and effective learning at UTP," Procedia - Social and Behavioral Sciences, vol. 56, pp. 594-601, 2012.

[29] V. A. Profillidis and G. N. Botzoris, "Statistical methods for transport demand modeling," Modeling of Transport Demand, Elsevier, Amsterdam, Netherland, pp. 163-224, 2019.

[30] C. Sotos, A. Elisa, S. Vanhoof, V. Noortgate, and O. Patrick, The Non-transitivity of Pearson' S Correlation Coefficient: An Educational Perspective, International Statistical Institute, Voorburg, Netherlands, 2007.

[31] D. L. Gilstrap, "Understanding persistence of at-risk students in higher education enrollment management using multiple linear regression and network analysis," The Journal of Experimental Education, vol. 88, no. 3, pp. 470-485, 2019.

[32] K.-H. Cheng and C.-C. Tsai, "Children and parents' reading of an augmented reality picture book: analyses of behavioral patterns and cognitive attainment," Computers \& Education, vol. 72, pp. 302-312, 2014. 
[33] J. J. Appleton, S. L. Christenson, and M. J. Furlong, "Student engagement with school: critical conceptual and methodological issues of the construct," Psychology in the Schools, vol. 45 , no. 5, pp. 369-386, 2008.

[34] J. D. Finn and K. S. Zimmer, "Student engagement: what is it? Why does it matter?," in Handbook of Research on Student Engagement, S. L. Christenson, A. L. Reschly, and C. Wylie, Eds., pp. 97-131, Springer Science + Business Media, 2012.

[35] F. Siddiq, P. Gochyyev, and O. Valls, "The role of engagement and academic behavioral skills on young students' academic performance-a validation across four countries," Studies In Educational Evaluation, vol. 66, Article ID 100880, 2020.

[36] D. Rozgonjuk, F. Schmitz, C. Kannen, and C. Montag, "Cognitive ability and personality: testing broad to nuanced associations with a smartphone app," Intelligence, vol. 88, Article ID 101578, 2021.

[37] S. L. Chan, C. C. Lin, P. H. Chau, N. Takemura, and J. T. C. Fung, "Evaluating online learning engagement of nursing students," Nurse Education Today, vol. 104, Article ID 04985, 2021.

[38] A. B. Bakker, "Strategic and proactive approaches to work engagement," Organizational Dynamics, vol. 46, no. 2, pp. 67-75, 2017.

[39] L. K. Fryer, A. Shum, A. Lee, and P. Lau, "Mapping students' interest in a new domain: connecting prior knowledge, interest, and self-efficacy with interesting tasks and a lasting desire to reengage," Learning and Instruction, vol. 75, Article ID 101493, 2021.

[40] H. Granziera and H. N. Perera, "Relations among teachers' self-efficacy beliefs, engagement, and work satisfaction: a social cognitive view," Contemporary Educational Psychology, vol. 58, pp. 75-84, 2019. 